\title{
SIGMOID PERFORATION - LPG TUBE FOUND ON EXPLORATION
}

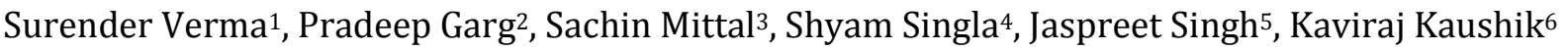

\section{HOW TO CITE THIS ARTICLE:}

Surender Verma, Pradeep Garg, Sachin Mittal, Shyam Singla, Jaspreet Singh, Kaviraj Kaushik. "Sigmoid Perforation - LPG Tube found on Exploration". Journal of Evolution of Medical and Dental Sciences 2014; Vol. 3, Issue 05, February 03; Page: 1188-1190, DOI: 10.14260/jemds/2014/1966

ABSTRACT: Most of recto-sigmoid injuries occur following impalement injuries by a variety of objects. Perforation caused by a Liquefied Petroleum Gas tube is not reported in literature. We report one such interesting case in which there was free LPG in peritoneal cavity as a result of perforation. It caught fire during opening of peritoneal cavity.

CASE SUMMARY: A 40 year old male patient was admitted in emergency with history of pain abdomen, distension \& vomiting of 6 hours duration. He was on treatment for a psychotic illness. He had a quarrel with his neighbors, who forced way in his house and four of them beat him. They forcibly introduced a pipe into his rectum and switched on the knob, following which he developed pain abdomen. He was rushed to emergency department.

On examination, he was found to have distension of the abdomen without any guarding or rigidity. A gentle proctoscopy revealed congested rectum with some bleeding. Erect film of the abdomen revealed free air under the diaphragm.

Abdomen was explored with midline incision. While electric cautery was being used to open the linea alba and peritoneum, a sudden flash of fire came towards surgeon's face, which surprised us all. The fire got extinguished within fraction of seconds without burning the skin of the patient and the operating team. There was a contusion along with color changes at the top of the sigmoid loop extending upto $5 \mathrm{~cm}$, with doubtful viability and perforation of $1.5-2 \mathrm{~cm}$ size in its center (Figure 1). In view of gross fecal contamination and contusion of sigmoid colon with perforation, sigmoid was excised, rectal stump was closed \& an end colostomy was done.

DISCUSSION: The rectum is known to have allowed misadventures by accommodating a variety of foreign bodies like fruits, candles, balls, kitchen articles, bottles and sticks. It is a known fact that some people use rectal insertion for gratification while others use it as a punishment method. Other variety of reasons include senility, intoxication, diagnostic or therapeutic instrumentation, selfadministered treatment, masturbation or as a part of joke. ${ }^{1-3}$ One interesting case of ingested chicken bone as a foreign body has also been reported in literature. ${ }^{4}$

There is a wide variety of reported foreign bodies that can cause colorectal injuries. ${ }^{5} \mathrm{LPG}$ as the source for sigmoid perforation has not been reported. LPG is made up of hydrocarbons that are gaseous at normal atmospheric pressure but may be condensed to the liquid state at normal temperature, by application of pressure. Although used as gases, they are stored and transported as liquids under pressure for convenience and ease of handling. One such form is gas cylinder, which is commonly used in household and commercial purposes.

LPG is non-poisonous, high calorific value fuel, which is predominantly a mixture of propane (60-90\%) and butane (10-30\%) with a small percentage of unsaturated (1-5\%) and some lighter $\mathrm{C}_{2}$ and heavier hydrocarbons like pentane. ${ }^{6}$ 
It is a combustible gas and needs air for the combustion. In our case it was lying free inside the peritoneal cavity and it caught fire while opening the peritoneum with electric cautery. Free atmospheric air helped it turned into flames.

Literature reveals rectum and recto sigmoid junction as the commonest site of perforation. The present case had sigmoid perforation which is rare. The proposed mechanism for this may be due to acute gaseous distention of the sigmoid colon due to LPG, leading to raised intra luminal pressure of sigmoid colon leading to perforation.

There is a universal agreement that there should be complete diversion of fecal stream with rectal injuries involving all layers. ${ }^{7}$ Hartmann's procedure is ideally suited for extensive rectal injuries. ${ }^{7}$

CONCLUSION: In traumatic recto sigmoid perforation, proper history should be sought preoperatively to find the exact cause to prevent any catastrophe to patient and diversion is better option to prevent morbidity.

\section{REFERENCE:}

1. Singla S, Chitkara N, Singh B, Garg P, Dhir V. Whisky bottle in the rectum. Indian J Gastroenterol. 1996; 15:113.

2. Busch DB, Starling JR. Rectal foreign bodies: case reports and a comprehensive review of the world's literature. Surgery. 1986; 100:512-9.

3. Lowicki EM. Accidental introduction of giant foreign body into the rectum: case report. Ann Surg. 1966; 163:395-8.

4. Davies DH. A chicken bone in the rectum. Arch Emerg Med. 1991; 8:62-4.

5. Clarke DL, Buccimazza I, Anderson FA, Thomson SR. Colorectal foreign bodies. Colorectal Dis. 2005; 7:98-103.

6. Guibet JC, Birchem EF. Fuels and Engines: Technology, Energy, Environment, Volume 2. $1^{\text {st }}$ ed. Paris. Institut Francais Du Petrole Publications. Chapter 6, alternative fuel; p.533-622.

7. Burch JM. Injury to the colon and rectum. In: Moore EE, Feliciano DV, Mattox KL, eds. Trauma. 5th ed. New York: McGraw Hill, 2004: 735-53.

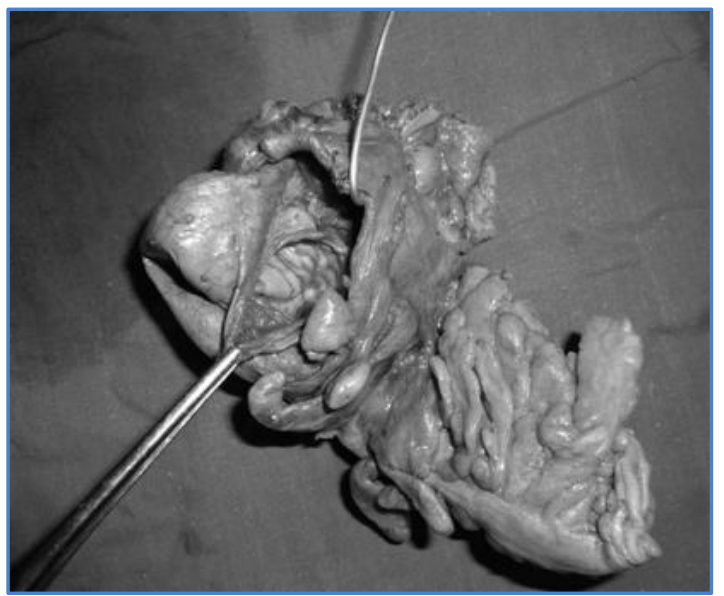

Fig. 1: diagram showing excised sigmoid showing perforation 


\section{AUTHORS:}

1. Surender Verma

2. Pradeep Garg

3. Sachin Mittal

4. Shyam Singla

5. Jaspreet Singh

6. Kaviraj Kaushik

\section{PARTICULARS OF CONTRIBUTORS:}

1. Senior Resident, Department of General Surgery, PGIMS, Rohtak.

2. Senior Professor, Department of General Surgery, PGIMS, Rohtak.

3. Senior Resident, Department of General Surgery, AIIMS, New Delhi.

4. Senior Professor, Department of General Surgery, PGIMS, Rohtak.
5. Junior Resident, Department of General Surgery, PGIMS, Rohtak.

6. Junior Resident, Department of General Surgery, PGIMS, Rohtak.

\section{NAME ADDRESS EMAIL ID OF THE CORRESPONDING AUTHOR:}

Dr. Pradeep Garg,

46/9 J, Medical Campus,

PGIMS, Rohtak, Haryana,

India, PIN - 124001.

E-mail: drpradeepgarg@rediffmail.com

Jaspreet.pgims@gmail.com

Date of Submission: 08/01/2014.

Date of Peer Review: 09/01/2014.

Date of Acceptance: 23/01/2014.

Date of Publishing: 29/01/2014. 